\title{
Monoterpenoids Concentration during Decomposition and Their Effect on Polysphondylium violaceum
}

\author{
Kim, Jong Hee*, Ji Young Hwang, Gyu Gap Jo and Ho Nam Kang \\ Division of Natural Sciences, College of Natural Sciences, Kyung Nam University, Masan 631-701, Korea
}

\begin{abstract}
The total monoterpenoid content of the pine litter layer and the availability of these compounds as inhibitors/stimulators on Polysphondylium violaceum of cellular slime molds were investigated. In order to determine the several monoterpenoids in the natural environment, we examined their concentrations in fresh, senescent, and decaying needles from 3 pine species (Pinus densiflora, $P$. thunbergii, $P$. rigida) by litter bag method. Total monoterpenoid content was highest in the fresh needles, but also remained relatively high in senescent needles. The effect of monoterpenoids identified from Pinus plants on the growth of $P$. violaceum was studied. We tested four concentrations $(1,0.1,0.01$, and $0.001 \mu \mathrm{g} / \mu \mathrm{L})$ of each compound by using a disk volatilization technique. Each compound was treated after germination of spores of $P$. violaceum. All of the compounds at $1 \mu \mathrm{g} / \mu \mathrm{L}$ concentration had a very strong inhibitory effect on cell growth of $P$. violaceum. Fenchone at all concentrations, myrcene, verbenone, bornyl acetate, and limonene at low concentrations stimulated the growth of $P$. violaceum. These results suggest that inhibitory or enhancing effects of selected monoterpenoids depend upon the concentration of the individual compound.
\end{abstract}

Key words: Decomposition, Inhibitory and enhancing effects, Monoterpenoids, Polysphondylium violaceum

\section{INTRODUCTION}

Conifers produce large quantities of monoterpenoids and sesquiterpenoids, which are released into the humus layer by littering and then they have an influence on soil microorganisms. The decomposition of monoterpenoids produced from plants is a complex process and has an interaction with chemical and physical properties of residues, soils and microorganisms. However, the decomposition of monoterpenoids in needle litter has been poorly studied (Kainulainen and Holopainen 2002). Isidorov and Jdanova (2002) studied that the most peculiar feature of the composition of litter volatile organic compound is the presence of many monoterpenoids. Kainulainen and Holopainen (2002) reported that after 19 months decomposition, the mass of monoterpenoids loss by pine needle litter was about $6 \%$ of the initial concentration. In the period of active decomposition, monoterpenoids excluded from pine needle litter remained in soils and affect soil microorganisms. In recently, the microbial transformation of monoterpenoid $R-(+)-\alpha$-terpineol into limonene by Penicillium sp. 2025 and Fusarium oxysporum 152B was investigated (Maróstoca and Pastore 2006). Van der Werf et al. (1996) and de Carvalho and da Fonseca (2006) have reviewed monoterpene biotransformation for the biotechnology and genetic engineering. These reviews give an important role as the high potential values for commercial production. Although no mo- noterpene biotransformation processes have been commercialized until now, in apparently, each monoterpenes have converted to the other ones by fungi, bacteria, and other microorganisms.

Chemical composition of plant residues can differ considerably, depending on plant species (Albers et al. 2004, Xu et al. 2006). Needle litter from pine is potentially a large contributor to the total monoterpenoids content, and the availability of these compounds are well known as phytotoxins (Paavolainen et al. 1998, Pardo et al. 1998, Dayan et al. 2000), and allelochemicals (Lodhi and Killingbeck 1980). Especially the activities of monoterpenoid on soil microorganisms involved in decomposition process have been researched (Isidorov and Jdanova 2002, Schmidt et al. 2000). Among the decomposer organisms, fungi play an important role in forest litter decomposition as they can contribute up to $90 \%$ of the total respiration of soil organisms (Kjøller and Struwe, 1982).

Cellular slime molds (CSMs) or dictyostelids common inhabitants of most litter-rich soils (Clark et al. 2002). They feed on bacteria, which decompose organic material from dead plants, especially fallen leaves and dead wood. Therefore, CSMs have an important role in the ecosystem of forest soil (Feest and Madelin 1998). CSMs have a simple and well-defined life cycle that has been often used in biochemical, genetic, and cell biological studies. When the food is exhausted, cells signal to each other and form aggregation territories which further differentiate into fruiting bodies containing stalk and spore cells. During the formation of

* Corresponding author; Phone: +82-55-249-2242, e-mail: biokim@kyungnam.ac.kr. 
fruiting bodies, Polysphondylium releases cell masses from the base of the culminating sorogen, and these masses soon form whorls of secondary fruiting bodies arrayed symmetrically about the central of primary stalk. The genus Polysphondylium was characterized by sorocarps with whorls of branches, which has been considered to be cosmopolitan and to be one of the dictyostelids characteristic of temperate and deciduous forest soils (Swanson et al. 1999).

In a previous investigation, Hwang and Kim (2004) found that monoterpenoids at all concentrations tested inhibited the growth of $P$. pallidum and the inhibitory effects of the monoterpenoids were represented by changes in the shapes of the fruiting bodies; very short sorophores, smaller sized sori and sori without spores compare to control. On the other hand, the growth of Dictyostelium discoideum NC4 was stimulated by some monoterpenoids (Hwang et al. 2004). They suggested that the cellular slime molds use the some monoterpenoids as carbon and energy sources as like the results from Vokou et al. (2002). It has been proposed that the effect of monoterpenoids from pine forest floor such differing results depend on the kinds of genus of CSM, compounds and their concentrations.

The aim of this study is (i) to investigate the changes in pine monoterpenoids concentrations during the processes of decomposition from fresh needle in the natural environment by litter bag method, (ii) to evaluate the inhibitory and/or stimulate effect of the pine monoterpenoids on the growth of $P$. violaceum.

\section{MATERIALS AND METHODS}

\section{Litter Bag Experiment}

This study was carried out in a natural forest of Pinus species at Mt. Bongrim Kyungnam Province, Korea. Annual precipitation was $1,733 \mathrm{~mm}$ in 2004 and mean monthly temperature ranged from $1.3^{\circ} \mathrm{C}$ (February) to $30.5^{\circ} \mathrm{C}$ (August) with a mean of $15.7^{\circ} \mathrm{C}$ over the study period. Fresh (green needles) and senescent (brown needles) were collected from Pinus densiflora, $P$. thunbergii, and $P$. rigida. The senescent needles that had recently abscised or fallen were collected off the top of the litter layer from each tree at November in 2004. Approximately $20 \sim 25 \mathrm{~g}$ of fresh needles was enclosed in litter bags $(20 \mathrm{~cm} \times 20 \mathrm{~cm})$ made of polypropylene shade cloth with a mesh size of $0.5 \mathrm{~mm}$. The litter bags were placed in the same plots as the collection of forest floor (top layers) and $20 \mathrm{~cm}$ below. The litter bags attached to the ground by metal pins to prevent movement and to ensure good contact between the bags and the organic layers. The decomposition study covered a 12-month period from April 2004 to April 2005. The bags were sampled 12 times at monthly intervals. On each sampling occasion, one bag was retrieved from each of the 9 subplots (for 3 species).
These were put in plastic bags and placed on ice for transport to the laboratory to analysis of monoterpenoids.

\section{Analysis of Monoterpenoids}

The decaying needles were prepared for analysis by gently removing the soil, and placing in a mortar with pure sand and extracted with $50 \mathrm{~mL}$ of pentane. After extraction, extracts from fresh needie and decaying needle samples were concentrated to 8 $10 \mathrm{~mL}$ and $0.5 \sim 1.0 \mathrm{~mL}$ under nitrogen gas, respectively. Each sample was analyzed by injection of $1 \mu \mathrm{L}$ aliquot onto a Gas Chromatography - Mass Spectrophotometer (HP 5890II-5972MS) with flame ionization detector. Monoterpenoids were separated on a fused silica capillary column packed with HP5 (id, $0.25 \mathrm{~mm}, 30$ $\mathrm{m}$ long) with oven temperature programmed from $37^{\circ} \mathrm{C}$ for five minutes, increased to $180{ }^{\circ} \mathrm{C}$ at a rate of $5{ }^{\circ} \mathrm{C} / \mathrm{min}$, then $20^{\circ} \mathrm{C} / \mathrm{min}$ to $320^{\circ} \mathrm{C}$.

The individual peaks were identified by comparison with the spectral data of the internal spectral library of the instrument (Wiley library ver. 7.0) and retention times, based on references. Because of the complexity of the chromatograms, a limited number of peaks were examined. The concentration of peaks at selected retention times were estimated from peak area using internal standard curve of tetradecane. Although we obtained many data from decay needles during decomposition, we report the variation of total monoterpenoids and main monoterpenoids of 3 pine species in this study. ANOVA was performed for the differences of monoterpenoids concentration during the decomposition periods in each species.

Isolating of CSM, Moterpenoids and Dilution

Soils containing CSM were taken from the humus and fermentation layers and processed with the method of Cavender and Raper (1965). Soil samples were collected from five sites of the forest floors on Mt. Muhak, Kyungnam Province, Korea.

Isolation of $P$. violaceum followed Hwang and Kim (2004). These plates were incubated at $20^{\circ} \mathrm{C}$. Two replicates per sample were prepared using both methods. The compounds we used were myrcene, $(R)-(+)$-limonene, $(-)$-menthone, $(S)$ - $(+)$-carvone, $(1 R)-(-)$ fenchone, $\alpha$-pinene, $(-)$-camphene, $(1 S)$ - $(-)$-verbenone, $\beta$-pinene, geranyl acetate and bornyl acetate. Each monoterpenoid was tested individually at four concentration $(1 \mu \mathrm{g} / \mu \mathrm{L}, 0.1 \mu \mathrm{g} / \mu \mathrm{L}, 0.01$ $\mu \mathrm{g} / \mu \mathrm{L}$, and $0.001 \mu \mathrm{g} / \mu \mathrm{L}$ ) levels, and then $1 \mu \mathrm{g}$ of each compound added on filter papers (Millipore hawp04700, $5 \mathrm{~mm}$ diameter). These concentrations and compounds are determined by the experiments for the P. pallidum (Hwang and Kim 2004), purchased from Aldrich Chemical Inc. and Fluka Chemical Company. Axenic liquid media (per liter, $14.3 \mathrm{~g}$ bacteriological peptone, 7.15 
g yeast extract, $30.8 \mathrm{~g} \mathrm{D}$-glucose, $1.28 \mathrm{~g} \mathrm{Na}_{2} \mathrm{HPO}_{4} \cdot 12 \mathrm{H}_{2} \mathrm{O}$, and $0.49 \mathrm{~g} \mathrm{KH}_{2} \mathrm{PO}_{4}$, final $\mathrm{pH} \mathrm{6.7)}$ as indicated by Watts and Ashworth (1970) was used for dilution, because the axenic solution alone does not cause inhibition or enhancement of CSM amoebae growth. The culture solution with no monoterpenoids was used as the control.

\section{The Effect of Compounds on Polysphondylium}

Because $P$, violaceum migrate after the myxamoebae are aggregated the clear zone could not form, and the characteristic of monoterpenoids is volatilization, we used was a disk volatilization technique (Hwang et al. 2004). This method used volatilization of selected monoterpenoids after germination of $P$. violaceum spores. The surfaces of $2 \%$ agar medium plates were inoculated with $E$. coli as a feeding source and $P$. violaceum. Since the inhibitory effect of monoterpenoid on the growth of $E$. coli has been reported (Alligiannis 2001, Thangadurai et al. 2002), we have a preliminary experiment for the effect of monoterpene on $E$. coli. The result of the preliminary experiment was no correlation between populations of $E$. coli and the growth of $P$. violaceum. Each compound was inoculated on filter paper disks (Millipore hawp04700, 5mm diameter) containing $1 \mu \mathrm{g}$ of diluted substance. The growth area of $P$. violaceum was measured by planimeter at $24 \mathrm{~h}$ intervals. We estimated the growth rate of a logarithmic growth area of each concentration by using the regression equation. The inhibition effects were recognized by a value lower than the rate of the control. All data were obtained from three replications of each experiment. Data were analyzed by using ANOVA, and LSD tests were performed for treatment effects at each concentration as well as the control.

\section{RESULTS}

\section{Quantification of Monoterpenoids in Decomposition}

Approximately 45 compounds were identified in the extracts of fresh needles from $P$. densiflora, 24 compounds from $P$. thunbergii, and 26 compounds from $P$. rigida. Total monoterpenoids content was highest in the fresh needles of $P$. densiflora $(519.4 \mu \mathrm{g} / \mathrm{g}), P$. thunbergii needles contained $408.6 \mu \mathrm{g} / \mathrm{g}$, and $P$. rigida had $168.8 \mu \mathrm{g} / \mathrm{g}$ of compounds. Although monoterpenoids compositions of each species were represented to different, but also common compounds identified in the fresh needles of 3 species; $\alpha$-pinene, $\beta$-pinene, $\beta$-phellandrene, bicycle heptan-2-ol, bicycloelemene, $\beta$-elemene, 1,4-methanoazulene. The decaying needles also contained similar monoterpenoids of fresh needles, but at substantially lower concentrations. Fig. 1 reveals that variations of total monoterpenoids of each species during decomposition. Significant differences were found in total monoterpenoids concentration and decomposition pe-

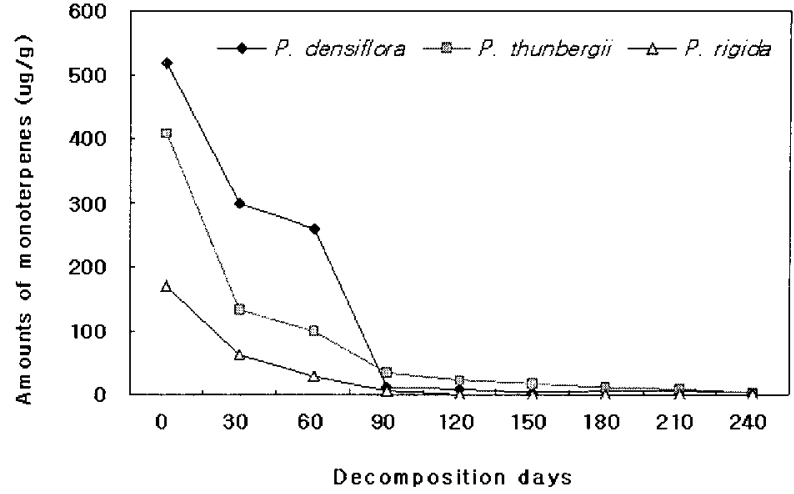

Fig. 1. The variation of total monoterpenoids of $P$. densiflora, $P$. thunbergii, and $P$. rigida needles during decomposition by litter bag method.

riod $(P<0.05$ for all 3 species). Total monotepenoids content was highest in the fresh needles in all 3 species, but also remained relatively high in decaying needles until 2 months. However, after 3 months the amounts of total monoterpenoids sharply decreased in all 3 species. And also, decaying needles within a litter material 20 $\mathrm{cm}$ below from the surface were found to contain much lower amounts of total monoterpenoids.

Table 1 lists the main common monoterpenoids identified in the senescent needles and decaying needles from 3 species. Compounds identified in the senescent needles of Pinus species included $\alpha$-pinene, $\beta$-pinene, $\beta$-myrcene, $\beta$-phellandrene, and bicycle-heptan$2-01$. Senescent needles included more than 50 compounds belonging to different classes of organic compounds; hydrocarbons, aldehydes, and ketones-containing sesquiterpenoids. However, the amounts of each compound were had very low or trace (data was not supplied in here). The data presented in Table 1 show that $\alpha$ -pinene $(11.38 \sim 16.42 \%), \beta$-pinene $(4.0 \sim 22.86 \%)$, and $\beta$-myrcene $(1.34 \sim 6.95 \%)$ levels of $P$. densiflora, $P$. thunbergii, and $P$. rigida can initially be present at relatively high concentrations in recently accumulated litter. Moreover, $\alpha$-pinene (4.49\%), $\beta$-pinene $(0.98 \%)$, and $\beta$-myrcene $(0.28 \%)$, and bicycle-heptan-2-ol $(0.14 \%)$ levels of $P$. densiflora, $a$-pinene (3.87\%), (3.17\%), and bicycle-heptan-2-ol $(0.38 \%)$ levels of $P$. thunbergii, and $\alpha$-pinene $(0.21 \%)$ level of $P$. rigida remained relatively in decaying needles that present in top layer soil, even though at the end of study period. However, the remaining compounds of below ground almost disappeared, excluding of $P$. densiflora.

The Effect of Monoterpenoids on the Growth Rate of $P$. violaceum

Results of the effect of monoterpenoids on growth rate of $P$. violaceum are shown in Table 2. All of the compounds at $1 \mu \mathrm{g} /$ 
Table 1. Main monoterpenoids (\%) of $P$. densiflora, $P$. thunbergii, and $P$. rigida needles. Data of decaying needles are obtained from the final samples at the end of study period

\begin{tabular}{|c|c|c|c|}
\hline & \multirow{2}{*}{$\begin{array}{l}\text { Senescent } \\
\text { needles }\end{array}$} & \multicolumn{2}{|c|}{ Decaying needles } \\
\hline & & Top layer & $20 \mathrm{~cm}$ below \\
\hline \multicolumn{4}{|l|}{ P. densiflora } \\
\hline$\alpha$-pinene & 11.38 & 4.49 & 0.93 \\
\hline$\beta$-pinene & 4.00 & 0.98 & 0.46 \\
\hline$\beta$-myrcene & 6.95 & 0.28 & 0.00 \\
\hline$\beta$-phellandrene & 0.00 & 0.00 & 0.33 \\
\hline Bicyclo heptan-2-ol & 0.55 & 0.14 & 0.00 \\
\hline \multicolumn{4}{|l|}{ P. thunbergii } \\
\hline$\alpha$-pinene & 11.42 & 3.87 & 0.00 \\
\hline$\beta$-pinene & 16.12 & 3.17 & 0.00 \\
\hline$\beta$-myrcene & 2.51 & 0.00 & 0.00 \\
\hline$\beta$-phellandrene & 0.05 & 0.00 & 0.00 \\
\hline Bicyclo heptan-2-ol & 0.30 & 0.38 & 0.00 \\
\hline \multicolumn{4}{|l|}{ P.rigida } \\
\hline$\alpha$-pinene & 16.32 & 0.21 & 0.00 \\
\hline$\beta$-pinene & 22.86 & 0.00 & 0.00 \\
\hline$\beta$-myrcene & 1.34 & 0.00 & 0.00 \\
\hline$\beta$-phellandrene & 0.03 & 0.00 & 0.00 \\
\hline Bicyclo heptan-2-ol & 0.57 & 0.00 & 0.00 \\
\hline
\end{tabular}

$\mu \mathrm{L}$ had a very strong inhibitory effect on cell growth in $P$. violaceum, resulting in a growth rate much lower than the control. However, the variable effects exhibited on growth rate of $P$. viola ceum, which depend on compounds and its concentrations. There were remarkably different results for $(1 S)-(-)$-verbenone $(0.17$ at $0.001 \mu \mathrm{g} / \mu \mathrm{L})$, fenchone $(0.22$ at $0.001 \mu \mathrm{g} / \mu \mathrm{L}, 0.87$ at $0.01 \mu \mathrm{g} /$ $\mu \mathrm{L}$, and 0.39 at $0.1 \mu \mathrm{g} / \mu \mathrm{L}$ concentration), and myrcene $(0.35$ at $0.01 \mu \mathrm{g} / \mu \mathrm{L})$ compared to the other monoterpenoids, which showed growth rates higher than the control (Table 2). Inhibitory effects on growth rates even at the lowest concentration were represented: geranyl-acetate, menthone $(P<0.05), \alpha$-pinene, and camphene $(P<0.001)$. And also our results at $0.01 \mu \mathrm{g} / \mu \mathrm{L}$ concentration show that $\beta$-pinene $(P<0.01)$, menthone and carvone $(P<$ 0.05 ) had inhibitory effects on the growth of $P$. violaceum. At 0.1 $\mu \mathrm{g} / \mu \mathrm{L}$ concentration, bornyl acetate, carvone, and limonene $(P<$ 0.001 ) had inhibitory effects on growth rate of $P$. violaceum. The rest of the compounds we used had no effects on growth of the Polysphondylium cells.
Table 2. Effect of monoterpenoids of $P$. violaceum the growth rate. Means designated with the same letter within a treatment are significantly different at $P<0.05^{\mathrm{a}}, 0.01^{\mathrm{b}}$, and 0.001 ${ }^{c}$ based on LSD test

\begin{tabular}{|c|c|c|c|c|c|}
\hline \multirow[b]{2}{*}{ Monoterpenoids } & \multicolumn{5}{|c|}{ Concentrations } \\
\hline & $\begin{array}{c}0.001 \\
\mu \mathrm{g} / \mu \mathrm{L}\end{array}$ & $\begin{array}{c}0.01 \\
\mu \mathrm{g} / \mu \mathrm{L}\end{array}$ & $\begin{array}{c}0.1 \\
\mu \mathrm{g} / \mu \mathrm{L}\end{array}$ & $\begin{array}{c}1 \\
\mu \mathrm{g} / \mu \mathrm{L}\end{array}$ & $\begin{array}{l}\text { Con- } \\
\text { trol }\end{array}$ \\
\hline Geranyl acetate & $-0.19^{2}$ & 0.06 & -0.04 & $-0.23^{2}$ & 0 \\
\hline$(1 S)-(-)$-Verbenone & $0.17^{2}$ & 0.05 & -0.07 & $-0.67^{\mathfrak{c}}$ & 0 \\
\hline$(1 R)-(-)$-Fenchone & $0.22^{\mathrm{a}}$ & $0.87^{\mathrm{c}}$ & $0.39^{\mathrm{e}}$ & $-0.42^{\mathfrak{c}}$ & 0 \\
\hline$(1 S)-(-)-\alpha$-Pinene & $-0.28^{\mathrm{c}}$ & -0.04 & -0.08 & $-0.71^{\mathfrak{c}}$ & 0 \\
\hline$(+)$ - $\beta$-Pinene & 0.04 & $-0.13^{b}$ & -0.06 & $-0.76^{\mathrm{c}}$ & 0 \\
\hline Myrcene & -0.14 & $0.35^{\mathrm{C}}$ & 0.02 & $-0.29^{a}$ & 0 \\
\hline (-)-Menthone & $-0.10^{2}$ & $-0.07^{\mathrm{a}}$ & -0.05 & $-0.61^{c}$ & 0 \\
\hline (-)-Bomyl acetate & 0.05 & $0.09^{\mathrm{a}}$ & $-0.23^{\mathrm{c}}$ & $-0.73^{\mathrm{c}}$ & 0 \\
\hline (S)-(+)-Carvone & -0.04 & $-0.13^{\mathrm{a}}$ & $-0.57^{c}$ & $-0.80^{\mathrm{c}}$ & 0 \\
\hline$(\mathrm{R})-(+)$-Limonene & $0.06^{\mathrm{a}}$ & 0.00 & $-0.10^{c}$ & $-0.20^{\mathrm{c}}$ & 0 \\
\hline (-)-Camphene & $-0.23^{c}$ & 0.01 & 0.04 & $-0.24^{c}$ & 0 \\
\hline
\end{tabular}

\section{DISCUSSION}

In general, degradation of pine needle litter is slow (Wilt et al. 1993). One of the reasons is either monoterpenoids or combinations of various monoterpenes inhibiting the activity of microbial and/or invertebrate decomposers as suggested by many researchers (White 1994, Hili et al. 1997, Paavolainen et al. 1998). Although volatile, monoterpenoids are initially present at relatively high concentration in recently fallen litter (Fig. 1), and the inhibitory effect of monoterpenoids on decomposers might be high in early decomposing process.

Our result (Fig. 2) also shows that all compounds at the highest concentration had strong inhibitory effects on the growth of rate, and the inhibition effect decreased as the low concentration of each compound. Therefore, these results suggest that growth of $P$. violaceum also might be inhibited in earlier decomposing process of pine needle, although $1 \mu \mathrm{g} / \mu \mathrm{L}$ concentration we used were not coincident with the amounts of forest floor litter. In fresh green needles and senescent brown needles of Scots pine most common monoterpenes were $\alpha$-pinene and 3-carene, and verbenone and verbenol were the most commonly identified compounds reported by Kainulainen and Holopainen (2002). In the natural senescent needles of 3 species, $\alpha$-pinene, $\beta$-pinene, and myrcene were always present in the high amounts (Table 1). The decaying needles also 
contained these some monoterpenoids, but at substantially lower concentrations. These compounds are not easily decreased in forest floors, because most monoterpenoids are not water-soluble and are not leached by rainwater. Our results also suggests that these compounds remained relatively high in decaying needles of top layers at the end of study period, and inhibited on the growth of $P$. violaceum.

On the other hand, Vokou et al. (2002) reported that fenchone, the major compound from Lanvandula stoechas, inhibited Bacillus subtilis, but didn't inhibit Escherichia coli or any of the soil microorganisms in their study. They suggested that E. coli and soil microorganisms used fenchone as a carbon and energy sources. Fenchone stimulated the growth rate of $P$. violaceum (Table 2) and D. discoideum NC4 (Hwang et al. 2004), but inhibited the growth of $P$. pallidum (Hwang and Kim 2004) even though at the lowest concentration. These results indicate that $P$. violaceum and $D$. discoideum NC4 might be use fenchone as an energy source for their life; $P$. pallidum might be not use the compound. Our experiments were not designed to examine whether these compounds can be used as an energy source. Nevertheless, on the basis of our results we could argue that fenchone, verbenone, and myrcene in presence of low concentration are potential carbon sources for $P$, violaceum, as suggested by Vokou et al. (2002), de Carvalho and da Fonseca (2006), and Demyttenaere et al. (2001). Therefore, soil microorganisms could use some of monoterpenoids in pine forest floor as nutrient sources and rapidly changed to other compounds by biodegradation during decomposition (Yoo et al. 2001, Phillips et al. 2003). Nevertheless, it is proposed that individual monoterpenoid may have entirely different activating of different target microorganisms.

Little studies are known about the decomposition process of monoterpenoids and uses of monoterpenoids by soil microorganisms. Especially, based on the finding of this study into the activity of monoterpenoids on $P$. violaceum, further research is needed to study whether or not monoterpenoids actually cause inhibition and/or enhance on growth of each species of soil microorganisms as well as CSM.

\section{ACKNOWLEDGEMENT}

This study has been supported by research funds from Kyungnam University.

\section{LITERATURE CITED}

Albers D, Migge S, Schaefer M, Scheu S. 2004. Decomposition of beech leaves (Fagus sylvatica) and spruce needles (Picea abies) in pure and mixed stands of beech and spruce. Soil Biol Biochem 36: $155-164$.

Alligiannis NE, Kalpoutakis SM, Chinou B. 2001. Composition and antimicrobial activity of the essential oil of two Origanum species. J Agric Food Chem 49:4168-4170.

Cavender JC, Raper KB. 1965. The Acrasieae in nature. $\square$. Forest soil as a primary habitat. Amer J Bot 52: 297-302.

Clark JD, Landolt JC, Stephenson SL. 2002. The effects of dictyostelids on the formation and maturation of myxomycete plasmodia. Mycologia 94: 933-938.

Dayan FE, Romagni JG, Duke SO. 2000. Investigating the mode of action of natural phytotoxins. J Chem Ecol 26: 2079-2094.

de Carvalho CCCR, da Fonseca MMR. 2006. Biotransformation of terpenes. Biotechnol Adv 24: 134-142.

Demyttenaere J, van Belleghem K, Dekimpe N. 2001. Biotransformation of $(\mathrm{R})-(+)$-and $(\mathrm{S})-(-)$-limonene by fungi and the use of solid phase microextraction for screening. Phytochemistry 57: 199-208.

Feest A, Madelin MF. 1998. Seasonal population change of myxomycetes and associated organisms in four woodland soils. FEMS Microbiol Ecol 53: 133-140.

Hili P, Evans CS, Veness RG. 1997. Antimicrobial action of essential oils: the effect of dimethylsulpnoxide on the activity of cinnamon oil. Lett Appl Microbiol 24: 269-275.

Hwang JY, Kim JH. 2004. The effect of monoterpenoids on growth of a cellular slime mold, Polysphondylium pallidum. J Plant Biol 47: $8-14$

Hwang JY, Kim JH, Yun KW, 2004. The effect of selected monoterpenoids on the cellular slime mold, Dictyostelium discoideum NC4. J Chem Ecol 30: 1153-1163.

Isidorov V, Jdanova M. 2002. Volatile organic compounds from leaves litter. Chemosphere 48: 975-979

Kjøller A, Struwe S. 1982. Microfungi in ecosystems: fungal occurrence and activity in litter and soil. Oikos 39: 389-422.

Kainulainen P, Holopainen JK. 2002. Concentrations of secondary compounds in scots pine needles at different stages of decomposition. Soil Biol Biochem 34: 37-42.

Lodhi MA, Killingbeck KT. 1980. Allelopathic inhibition of nitrification and nitrifying bacteria in a ponderosa pine (Pinus ponderosa Dougl.) community. Am J Bot 67: 1423-1429.

Maróstoca Jr MR, Pastore GM. 2006. Production of $R-(+)-\alpha$-terpineol by the biotransformation of limonene from orange essential oil, using cassava waste water as medium. Food Chem DOI 10. 1016/j.foodchem. 2005.12.056.

Paavolainen L, Kitunen V, Smolander A. 1998. Inhibition of nitrification in forest soil by monoterpenes. Plant Soil 205:147-154.

Pardo F, Perich F, Torres R, Delle Monache, F. 1998. Phytotoxic iridoid glucosides from the roots of Verbascum thapsus. J Chem Ecol 24: 645-653.

Phillips MA, Wildung MR, Williams DC. 2003. cDNA isolation, functional expression, and characterization of $(+)-\alpha$-pinene syntase and $(-)-\alpha$-pinene synthase from loblolly pine (Pimus taeda): Stereocontrol in pinene biosynthesis. Archiv Biochem Biophys 411: 267-276.

Schmidt SK, Lipson DA, Raab TK. 2000. Effects of willows (Salix brachycarpa) on populations of salicylate-mineralizing microor- 
ganisms in alpine soils. J Chem Ecol 26: 2049-2057.

Swanson AR, Vadell EM, Cavender JC. 1999. Global distribution of forest soil dictyostelids. J Biogeogr 26: 133-148.

Thangadurai D, Anitha S, Pullaiah T, Reddy PN, Ramachandraiah OS. 2002. Essential oil constituents and in vitro antimicrobial activity of Decalepis hamiltonii roots against foodborne pathogens. J Agric Food Chem 50: 3147-3149.

van der Werf MJ, de Bont JAM, Leak DJ. 1996. Opportunities in microbial biotransformation of monoterpenes. In: Biotechnology of aroma compounds, (Berger RG, eds.). Springer, Berlin, pp 147-177.

Vokou D, Chalkos D, Karamananlidou G, Yiangou M. 2002. Activation of soil respiration and shift of the microbial population balance in soil as a response to Lanvandula stoechas essential oil. J Chem Ecol 28: 755-768.

Watts DJ, Ashworth JM (1970) Growth of myxamoebae of the cellular slime mold Dictyostelium discoideum in axenic culture. Biochem J 119:171-174.

Wilt FM, Miller GC, Everett RL, Hackett M. 1993. Monoterpene concentrations in fresh, senescent, and decaying foliage of single-leaf pinyon (Pinus monophylla Yorr. \& Frem.: Pinaceae) from the western Great Basin. J Chem Ecol 19: 185-194.

White CS. 1994. Monoterpenes: their effects on ecosystem nutrient cycling. J Chem Ecol 20: 1381-1406.

$\mathrm{Xu}$ JM, Tang C, Chen ZL. 2006. Chemical composition controls residue decomposition in soils differing in initial pH. Soil Biol Biochem 38: 544-552.

Yoo SK, Day DF, Cadwallader KR. 2001. Bioconversion of $\alpha$ - and $\beta$-pinene by Pseudomonas sp. strain PIN. Process Biochem 36: 925-932.

(Received May 9, 2006; Accepted July 18, 2006) 